\title{
General Psychiatry Psychosis as an indicator of recurrent non-Hodgkin's lymphoma: a rare presentation
}

\author{
Mustafa Ali, Soumitra Das
}

To cite: Ali M, Das S. Psychosis as an indicator of recurrent non-Hodgkin's lymphoma: a rare presentation. General Psychiatry 2018;31:e000005. doi:10.1136/ gpsych-2018-000005

- Prepublication history and additional material for this paper are available online. To view these files, please visit the journal online (http://dx.doi.org/ 10.1136/gpsych-2018-000005)

Received 17 January 2018 Revised 13 February 2018 Accepted 22 May 2018
Check for updates

(C) Author(s) (or their employer(s)) 2018 . Re-use permitted under CC BY-NC. No commercial re-use. See rights and permissions. Published by BMJ.

Department of Psychiatry, National Institute of Mental Health and Neurosciences, Bangalore, India

Correspondence to

Soumitra Das;

soumitratdmc@gmail.com

\section{SUMMARY}

Psychotic manifestations of brain tumours are rare but described in the literature mostly along with other neurological deficits. Memory loss, difficulty in attention and concentration, depression, anxiety, and mood symptoms are commonly described in brain tumours. A schizophrenia-like picture without a deficit in motor or sensory function may land the clinician into a diagnostic dilemma. Primary central nervous system lymphoma (PCNSL) is a highly malignant disease with high mortality and needs immediate attention. Our case which had a unique recurrence in the postoperative period with psychotic symptoms can be an eye-opener to be more vigilant about underlying clinical extension.

\section{INTRODUCTION}

Brain tumours are relatively common with an annual incidence of 9 per 100000 people for primary brain tumours and 8.3 per 100000 people for metastatic brain tumours. Based on histopathological characteristics and anatomical location, there are two types of tumours: ones that are primary, originating from the brain tissue; and ones that metastasise to numerous locations throughout the brain. The most common primary brain tumours are gliomas, which are divided into several types: astrocytomas, oligodendrogliomas, and ependymomas. The groups of brain tumours that are not from the glial tissue include meningiomas, schwannomas, craniopharyngiomas, germ cell tumours, pituitary adenomas and pineal region tumours. ${ }^{1}$ Primary CNS lymphoma (PCNSL) accounts for $3 \%$ of all primary brain tumours with a median age at onset of about 62 years. In the vast majority of cases, PCNSL presents as unifocal or multifocal enhancing lesions on MRI, frequently adjacent to the ventricles. Stereotactic biopsy is the diagnostic procedure of choice revealing high-grade B-cell non-Hodgkin's malignant lymphomas in more than $90 \%$ of cases. ${ }^{2}$ Patients with brain tumour usually manifest with features of raised intracranial pressure, focal neurological deficits, and seizures. Psychotic manifestations are not usually seen. Brain tumours may present with psychotic symptoms that resemble schizophrenia. Although psychosis secondary to brain tumour is relatively rare, the frequent lack of neurological findings can lead to misdiagnosis.

Here we are presenting a case where recurrence of lymphoma was linked with psychotic symptoms without the appearance of any neurological deficit.

\section{CASE REPORT}

A 65-year-old man presented with suddenonset ataxic deviation of angle of mouth to the left side, right upper and lower limb weakness, urinary incontinence, slurred speech with no history of fever, headache, blurred vision, convulsion, vomiting, or loss of consciousness. On neurological examination the patient was conscious and oriented to time, person, and place. Vitals: stable; pupil: $\mathrm{B} / \mathrm{L}$ equal and reactive; tone: increased in right upper limb (UL) and lower limb (LL); power: right UL and LL is $3 / 5$ while in left $\mathrm{UL}$ and LL is $5 / 5$; plantar: right is flexion while left is extension. The MRI T1 showed intense homogeneous enhancement in the left frontal and medial temporal lobes. In T2 slide it was hypotense with minimal ring enhancement. In diffusion weighted MR imaging (DWI), the apparent diffusion coefficient (ADC) value was 500. Craniotomy and decompression surgery was considered for the lesion. Basic blood investigation was done before undergoing surgery which was within normal limit. A histopathological report revealed fragments of cortical and subcortical white matter infiltrated by sheets of atypical lymphoid cells which were medium-sized to large-sized with high nucleus- cytoplasm (N:C) ratio, scant cytoplasm, and vesicular nuclei with one to two prominent nucleoli exhibiting moderate anisonucleosis. Brisk mitosis and apoptosis were observed. Areas of haemorrhage, necrosis and angiocentric 
arrangement by these cells were noted. Immunohistochemical (IHC): tumour cells were diffusely positive for leukocyte common antigen (LCA) and CD20. Reactive lymphocytes are highlighted by cluster of differentiation 3 (CD3). MIB (proliferation marker)—one labelling index was very high $(80 \%)$.

Our final impression was non-Hodgkin's lymphoma 'B' cell type. Consistent with diffuse large B cell lymphoma; left frontal and medial temporal.

The patient showed good improvement in his neurological deficits postsurgery and was discharged on antiepileptics. After 6 months of surgery the patient showed behavioural problems characterised by irritability, irrelevant speech, disorganised behaviour, disinhibitory behaviour, and delusion of misinterpretation along with disturbed biological functions. His orientation and consciousness were preserved. He was unable to do routine functions and needed help from caregivers because of his disorganised behaviour. He had no prior history of psychosis. There was no history of the reappearance of the neurological deficit this time. On neuroimaging, it was found that there was a relapse of lymphoma in the frontal lobe which was supposed to disappear after surgery. Surprisingly there was no symptom of increased intracranial tension. He was placed on antipsychotic medication by the psychiatric service and the patient showed improvement in his symptoms over a period of 6 months.

\section{DISCUSSION}

PCNSL is a highly malignant disease which may rapidly lead to mortality if diagnosis and treatment are not immediately administered. ${ }^{3}$ The patient with PCNSL presented with a variety of clinical manifestations both psychiatric as well as neurological deficits. Eichler AF has found that $43 \%$ of the patients have neuropsychiatric symptoms during the course of PCNSL. ${ }^{4}$ Though rare, some brain tumours present themselves through neurobehavioural or psychiatric symptoms only. Hallucinations and even psychosis have been reported in patients with brain tumour. ${ }^{5}$ Currently, there is no evidence of a causative relationship between classical paranoid schizophrenia and brain tumours. Although large studies are lacking, there are indications that idiosyncratic psychoses can occur after resection of the (mesial) temporal lobes. Case studies describe acute psychosis, agitation and suicidal/ homicidal ideations with paranoia following surgery. ${ }^{6}$ But there is a probable association between psychotic symptoms and pituitary tumours, memory symptoms and thalamic tumours, and mood symptoms and frontal tumours. ${ }^{1}$

Here, our case is important as relapse was associated with only psychiatric manifestation without any neurological deficit. The symptoms of disinhibition along with it could be due to frontal lobe involvement. Moreover, the relationship between emergence of psychotic symptoms in a patient with no past or family history is pathognomonic of organic psychosis as it was associated with new MRI changes. As the patient was presenting with confusion, we could rule out the disinhibited behaviour secondary to delirium. This case tells us to be vigilant when there is an emergence of psychosis in the postoperative period as this could be a recurrence of the carcinoma rather than simple delirium.

Contributors All authors contributed to the drafting of this manuscripts.

Funding The authors have not declared a specific grant for this research from any funding agency in the public, commercial or not-for-profit sectors.

Competing interests None declared.

Patient consent Obtained.

Provenance and peer review Not commissioned; externally peer reviewed

Open access This is an Open Access article distributed in accordance with the Creative Commons Attribution Non Commercial (CC BY-NC 4.0) license, which permits others to distribute, remix, adapt, build upon this work non-commercially, and license their derivative works on different terms, provided the original work is properly cited and the use is non-commercial. See: http://creativecommons.org/ licenses/by-nc/4.0

\section{REFERENCES}

1. Madhusoodanan S, Danan D, Moise D. Psychiatric manifestations of brain tumors: diagnostic implications. Expert Rev Neurother 2007;7:343-9.

2. Schlegel U. Primary CNS Iymphoma. Ther Adv Neurol Disord 2009;2:93-104.

3 DeAngelis LM. Brain tumors. N Engl J Med 2001;344:114-23.

4. Eichler AF, Batchelor TT. Primary central nervous system lymphoma: presentation, diagnosis and staging. Neurosurg Focus 2006;21:1-9.

5. Filley CM, Kleinschmidt-DeMasters BK. Neurobehavioral presentations of brain neoplasms. West J Med 1995;163:19-25.

6. Shah $\mathrm{AH}$, Gordon $\mathrm{CE}$, Bregy A, et al. Considering iatrogenic psychosis after malignant glioma resection. BMJ Case Rep 2014;2014.

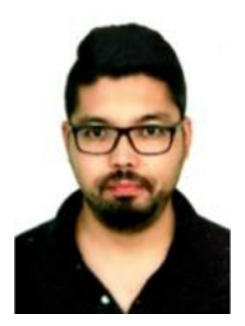

Mustafa Ali graduated from the Government Medical College, Srinagar, Jammu and Kashmir, India in 2012. He has been working at the National Institute of Mental Health and Neurosciences, Bangalore, India since 2015. Now he is working as a resident doctor in the department of psychiatry. His research interests include schizophrenia, bipolar disorder, and deaddiction. 